\title{
Aligned carbon nanotubes/fibers for applications in vacuum microwave amplifiers
}

\author{
W. I. Milne and K. B. K. Teo ${ }^{a}$ \\ Department of Engineering, University of Cambridge, Trumpington Street, Cambridge CB2 1PZ, \\ United Kingdom \\ E. Minoux \\ Thales Research and Technology, Route Départmental 128, 91767 Palaiseau Cedex, France \\ O. Groening \\ Federal Laboratories for Materials Testing and Research, EMPA Thun, Switzerland \\ L. Gangloff, L. Hudanski, J.-P. Schnell, D. Dieumegard, and F. Peauger \\ Thales Research and Technology, Route Départmental 128, 91767 Palaiseau Cedex, France \\ I. Y. Y. Bu and M. S. Bell \\ Department of Engineering, University of Cambridge, Trumpington Street, Cambridge CB2 1PZ, \\ United Kingdom \\ P. Legagneux \\ Thales Research and Technology, Route Départmental 128, 91767 Palaiseau Cedex, France \\ G. Hasko \\ Microelectronics Research Centre, University of Cambridge, Madingley Road, Cambridge CB3 OHE, \\ United Kingdom
}

G. A. J. Amaratunga

Department of Engineering, University of Cambridge, Trumpington Street, Cambridge CB2 1PZ, United Kingdom

(Received 28 April 2005; accepted 28 November 2005; published 25 January 2006)

\begin{abstract}
Most long-range telecommunication systems are based upon microwave links. The transmitters use microwave amplifiers which in the very near future will be required to work at up to $30-100 \mathrm{GHz}$ with output power in the region of a few tens of watts. Carbon nanotubes (CNTs), which exhibit extraordinary field emission properties because of their high electrical conductivity, ideal high aspect ratio whisker-like shape for geometrical field enhancement, and remarkable thermal stability, can be used as the emitter in such applications. This article will describe the plasma enhanced chemical vapor deposition growth of vertically aligned carbon nanotubes, and how well controlled arrays of such structures can be grown. We will also describe how high current densities of $\sim 1 \mathrm{~A} / \mathrm{cm}^{2}$, under direct current and $1.5 \mathrm{GHz}$ direct modulation, can be obtained from CNT cathodes. These CNT cold cathodes offer considerable weight and size savings over conventional hot cathodes used in microwave applications (e.g., SATCOM, radar). () 2006 American Vacuum Society. [DOI: 10.1116/1.2161223]
\end{abstract}

\section{INTRODUCTION}

Most long range telecom systems utilize microwave transmission links. With requirements for higher bandwidth and more channels, these microwave links are increasingly using the $30 \mathrm{GHz}$ and above frequency range. In order to satisfy the power (tens of watts) and bandwidth requirements (30 GHz) for long range communications, satellites are using traveling wave tubes (TWTs) based on thermionic cathodes. Traveling wave tubes, however, are bulky and heavy, and take up valuable space and weight budget in a satellite. Any miniaturization of the current TWT would give rise to cost savings in a satellite launch, and aid the implementation of microsatellites. Solid state devices are not used in this high

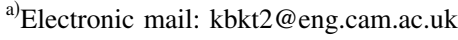

frequency, high bandwidth regime (see Fig. 1) because the maximum power attained by solid state devices today at $30 \mathrm{GHz}$ is about $1-10 \mathrm{~W}$.

Attempts have been made to replace the hot thermionic cathode in a TWT with a Spindt tip cathode-however, the bulk of the TWT device is still there, since it is the tube (in which the electron beam modulation takes place) that is physically large. The most effective way to reduce the size of a TWT is via direct modulation of the electron (e) beam, for example, in a triode configuration. Cold cathodes with the ability of being modulated at $30 \mathrm{GHz}$ do not presently exist. "Spindt tip" technology suffers because it employs an integrated grid system where the spacing between the cathode and grid is filled with an insulator (typically $\mathrm{SiO}_{2}$ or $\mathrm{Al}_{2} \mathrm{O}_{3}$ ), which leads to high capacitance (due to short cathode-grid distance and permittivity of the dielectric), and hence, they could only be used to provide the primary [direct current 


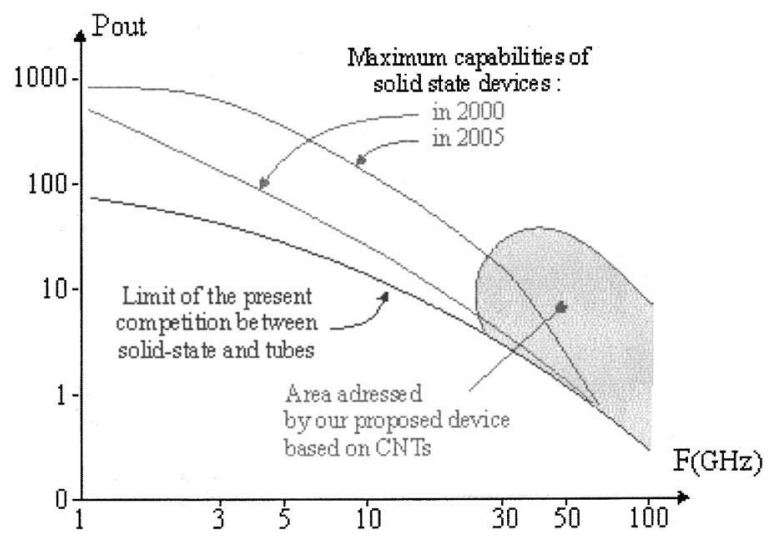

FIG. 1. Power/frequency diagram of solid state and electronic tube device.

(dc)] beam of a TWT. In the case of a carbon nanotube (CNT) array, the grid is not integrated and can be located at a standoff distance of $10-100 \mu \mathrm{m}$ from the emitters where the space between emitter and grid is vacuum with a consequent reduction in grid/cathode capacitance of the order of 20-50 times, allowing for high frequency operation of the grid. The European Commission funded project CANVAD aims to develop gigahertz field emitter devices based on such directly modulated CNT cathodes. A schematic of a triodetype amplifier is shown in Fig. 2. To be competitive with thermionic cathodes, the CNT cathode should deliver current densities in the range $\sim 1-2 \mathrm{~A} / \mathrm{cm}^{2}$; in real terms, a few milliamperes of directly modulated current is required which can be accelerated over a few kilovolts to the anode to give the tens of watts required in a telecommunications amplifier.

\section{EXPERIMENT}

Typical "spaghetti" type CNT films cannot produce the emission current densities required. We need to produce aligned arrays of CNTs (see, for example, Fig. 3) in order to obtain the required emission current densities as described recently by Milne et al. ${ }^{1}$

In order to produce these arrays, well defined $\mathrm{Ni}$ catalyst dots are deposited on top of a TiN barrier layer using e-beam lithography. Typically, we use Ni dots of $100 \mathrm{~nm}$ diameter which produce CNTs of diameter $\sim 50 \mathrm{~nm}$ as previously reported. ${ }^{2}$ In order to produce the vertical aligned structures, a plasma enhanced chemical vapor deposition (PECVD) process as described previously ${ }^{3}$ is required. In house, we have a variety of systems based on dc-PECVD which are capable

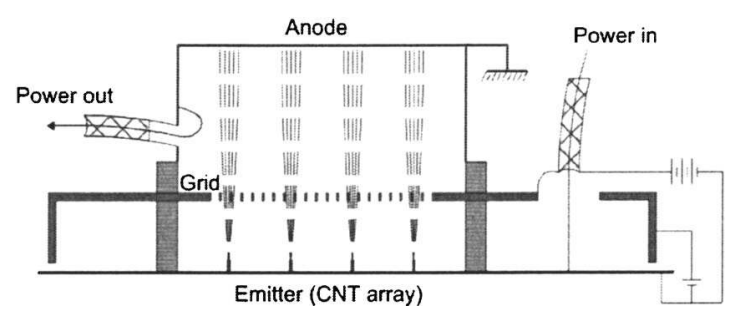

FIG. 2. Schematic of a CNT based vacuum microwave amplifier based on a rf triode.

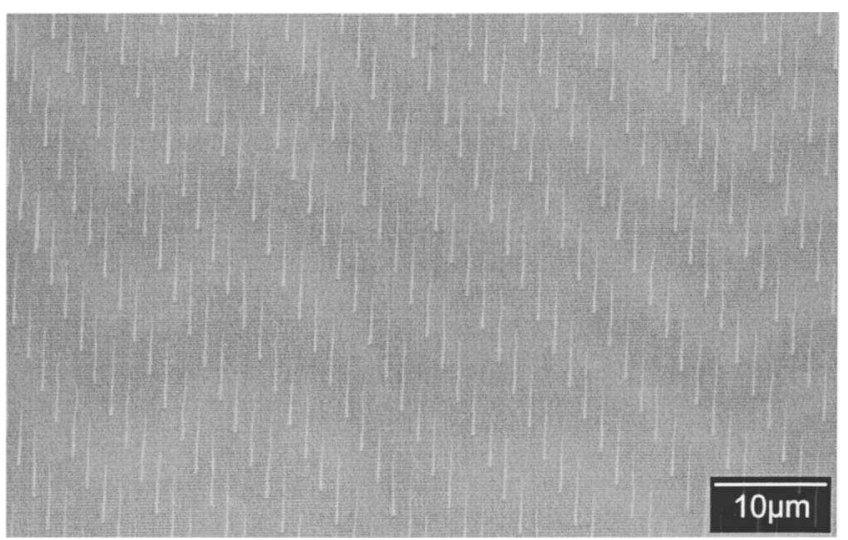

FIG. 3. Highly uniform vertically aligned CNT arrays with typical standard deviation of $4 \%$ in the diameter and $6 \%$ in the height.

of growing such vertically aligned carbon nanotubes. Figure 4(a) below shows a high power $(200 \mathrm{~W})$ PECVD system which uses plasma heating to achieve the CNT growth at high induced temperatures. Figure 4(b) shows a low power $(<20 \mathrm{~W})$ PECVD system that uses a substrate heater to achieve CNT growth at elevated temperatures. In addition to these two systems demonstrating the high power/lower power PECVD ends of the process, we also have lowcharging/non-dc PECVD versions of CNT growth systems developed for growth on insulating materials such as substrates coated with $\mathrm{SiO}_{2}$, glass, and ceramics. Typical growth conditions can be found in Ref. 3 .

Using optimized arrays of such nanotubes with heights of $5 \mu \mathrm{m}$ and diameter $50 \mathrm{~nm}$ and a spacing of $10 \mu \mathrm{m}$ we have obtained an emission current of $2.5-3 \mathrm{~mA}$ over 500 $\times 500 \mu \mathrm{m}^{2}$ at both $\mathrm{dc}$ and $1.5 \mathrm{GHz}$ radio frequency (rf) modulation (corresponding to $1 \mathrm{~A} / \mathrm{cm}^{2}$ ) as shown in Figs. 5 and 6 (see Ref. 4).

Our high emission current/current density is a result of two factors-first, our nanotubes are extremely uniform in structure, leading to a narrow field enhancement distribution. This allows us to simultaneously turn on most of the emitters simultaneously to attain a high peak current. Second, the cathodes undergo a rapid thermal annealing step at $850{ }^{\circ} \mathrm{C}$, prior to integration into the devices. This has a twofold effect in improving the crystalline structure (i.e., reducing the intrinsic resistance) of the CNTs and also reducing the contact resistance between the CNT/TiN/substrate (Ref. 5).
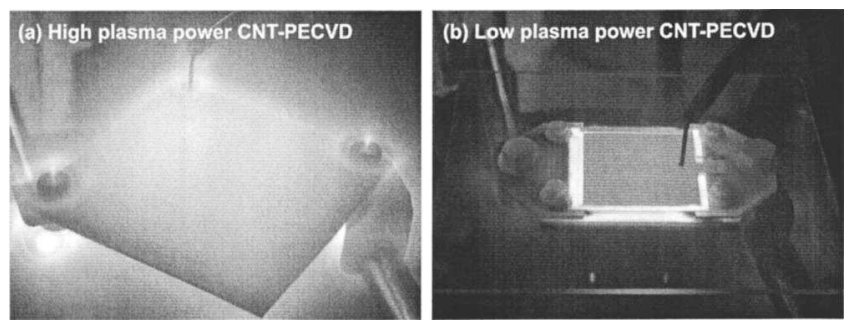

FIG. 4. CNT PECVD systems (a) high plasma power and (b) low plasma power. 


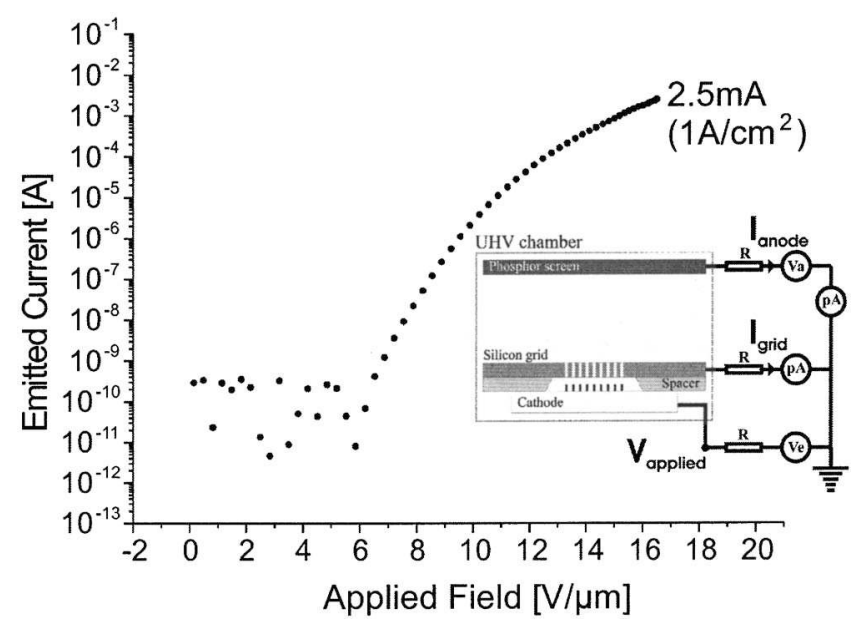

FIG. 5. Emitted current vs applied field.

Furthermore, a higher emission current density can in theory be attained by maintaining the same aspect ratio but by having a smaller diameter CNT with shorter length - this causes less voltage drop (and also less heating) across the CNTs. We are presently adopting a variety of strategies to achieve this. One particular method is to deposit the CNTs under the same lithographic conditions, which previously led to a $50 \mathrm{~nm}$ tip diameter, but then to carry out a post deposition etch using $\mathrm{NH}_{3}$ at $700{ }^{\circ} \mathrm{C}$, similar to the process described in Ref. 6. As shown in Fig. 7, the tip diameter has been etched from $50 \mathrm{~nm}$ down to $30 \mathrm{~nm}$. The height of the structures is directly proportional to the growth time, and this is controlled to be in the $3 \mu \mathrm{m}$ range to maintain the same aspect ratio as the previously tested CNTs of $50 \mathrm{~nm}$ diameter and $5 \mu \mathrm{m}$ height. Work is also currently underway to design a $30 \mathrm{GHz}$ triode based on a directly modulated CNT cold cathode (Refs. 7-20).

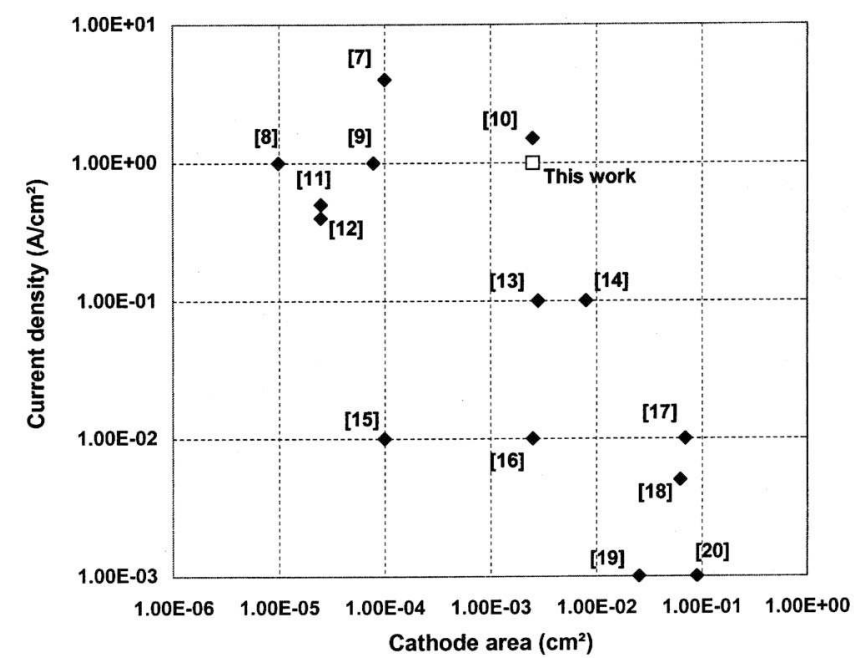

FIG. 6. Current density vs area of our CNT cathode and other reported CNT cathodes.
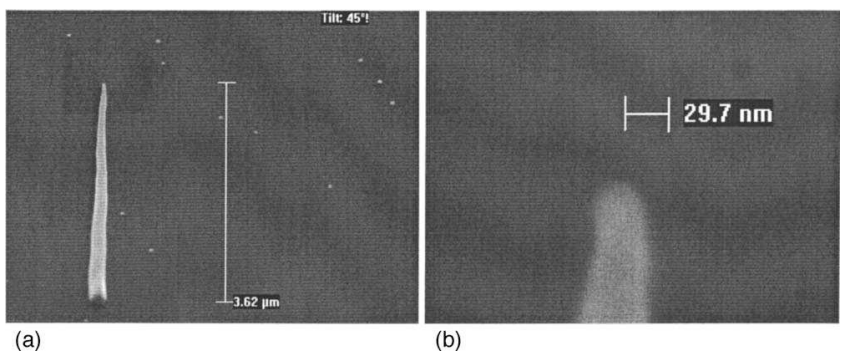

FIG. 7. (a) Low magnification view of a CNT which has been etched with $\mathrm{NH}_{3}$ at $700{ }^{\circ} \mathrm{C}$. (b) High magnification view shows that the tip of the CNT has been etched to $\sim 30 \mathrm{~nm}$ in diameter.

\section{CONCLUSIONS}

We have investigated CNTs as the electron emitters for high current/high frequency microwave amplifiers. By careful optimization of the shape and distribution of the CNT arrays we have obtained emission current densities of $1 \mathrm{~A} / \mathrm{cm}^{2}$ at $\mathrm{dc}$ and $1.5 \mathrm{GHz}$. Work is in progress to develop a triode operating at $30 \mathrm{GHz}$ and to further increase the emission current density.

\section{ACKNOWLEDGMENTS}

The work was partially funded by the E.C. through the IST-FET project CANVAD and by the EPSRC Carbon Based Electronics initiative. K.B.K.T. acknowledges the funding of the Royal Academy of Engineering and Christ's College Cambridge.

This paper was presented at the First International Workshop on One Dimensional Materials, 10-14 January 2005, National Taiwan University, Taipei, Taiwan.

${ }^{1}$ W. I. Milne, K. B. K. Teo, G. A. J. Amaratunga, P. Legagneux, L. Gangloff, J.-P. Schnell, V. Semet, V. T. Binh, and O. Goening, J. Mater. Chem. 14, 933 (2004).

${ }^{2}$ K. B. K. Teo, S.-B. Lee, M. Chhowalla, V. Semet, V. T. Binh, O. Groening, M. Castignolles, A. Loiseau, G. Pirio, P. Legagneux, D. Pribat, D. G. Hasko, H. Ahmed, G. A. J. Amaratunga, and W. I. Milne, Nanotechnology 14, 204 (2003).

${ }^{3}$ M. Chhowalla, K. B. K. Teo, C. Ducati, N. L. Rupesinghe, G. A. J. Amaratunga, A. C. Ferrari, D. Roy, J. Robertson, and W. I. Milne, J. Appl. Phys. 90, 5308 (2001).

${ }^{4}$ K. B. K. Teo, E. Minoux, L. Hudanski, F. Peauger, J.-P. Schnell, L. Gangloff, P. Legagneux, D. Dieumegard, G. A. J. Amaratunga, and W. I. Milne, Nature (London) 437, 968 (2005).

${ }^{5}$ E. Minoux, O. Groening, K. B. K. Teo, S. H. Dalal, L. Gangloff, J.-P. Schnell, L. Hudanski, I. Y. Y. Bu, P. Vincent, P. Legagneux, G. A. J. Amaratunga, and W. I. Milne, Nano Lett. 5, 2135 (2005).

${ }^{6}$ V. I. Merkulov, A. V. Melechko, M. A. Guillorn, D. H. Lowndes, and M. L. Simpson, Chem. Phys. Lett. 350, 381 (2001).

${ }^{7}$ W. Zhu, C. Bower, O. Zhou, G. Kochanski, and S. Jin, Appl. Phys. Lett. 75, 873 (1999).

${ }^{8}$ A. M. Rao, D. Jacques, R. C. Haddon, W. Zhu, C. Bower, and S. Jin, Appl. Phys. Lett. 76, 3813 (2000).

${ }^{9}$ X. Xu and G. R. Brandes, Appl. Phys. Lett. 74, 2549 (1999).

${ }^{10}$ F. G. Tarntair, L. C. Chen, S. L. Wei, W. K. Hong, K. H. Chen, and H. C. Cheng, J. Vac. Sci. Technol. B 18, 1207 (2000).

${ }^{11}$ C. Bower, W. Zhu, D. Shalom, D. Lopez, L. H. Chen, P. L. Gammel, and S. Jin, Appl. Phys. Lett. 80, 3820 (2002).

${ }^{12}$ P. G. Collins and A. Zettl, Appl. Phys. Lett. 69, 1969 (1996).

${ }^{13}$ Yu. V. Gulyaev, L. A. Chernozatonskii, Z. Ja. Kosakovskaja, N. I. Sinitsyn, G. V. Torgashov, and Yu. F. Zakharchenko, J. Vac. Sci. Technol. 
B 13, 435 (1995).

${ }^{14}$ W. A. De Heer, A. Châtelain, and D. Ugarte, Science 270, 1179 (1995).

${ }^{15}$ H. Sato, H. Takegawa, and Y. Saito, J. Vac. Sci. Technol. B 21, 2564 (2003).

${ }^{16}$ S. Fan, M. G. Chapline, N. R. Franklin, T. W. Tombler, A. M. Cassel, and H. Dai, Science 283, 512 (1999).

${ }^{17}$ J.-M. Bonard, J.-P. Salvetat, T. Stöckli, W. A. de Heer, L. Forró, and A.
Châtelain, Appl. Phys. Lett. 73, 918 (1998).

${ }^{18}$ A. N. Obraztsov, I. Pavlovsky, A. P. Volkov, E. N. Obraztsova, A. L. Chuvilin, and V. L. Kuznetsov, J. Vac. Sci. Technol. B 18, 1059 (2000).

${ }^{19}$ Q. H. Wang, T. D. Corrigan, J. Y. Dai, R. P. H. Chang, and A. R. Krauss, Appl. Phys. Lett. 70, 3308 (1997).

${ }^{20} \mathrm{H}$. Murakami, M. Hirakawa, C. Tanaka, and H. Yamakawa, Appl. Phys. Lett. 76, 1776 (2000). 